\title{
Temperature log simulations in high-enthalpy boreholes
}

\author{
Jia Wang ${ }^{*}$ (D), Fabian Nitschke, Maziar Gholami Korzani and Thomas Kohl
}

\author{
${ }^{*}$ Correspondence: \\ jia.wang@kit.edu \\ Institute of Applied \\ Geoscience, Karlsruhe \\ Institute of Technology \\ (KIT), Adenauerring 20b, \\ 76131 Karlsruhe, Germany
}

\begin{abstract}
Temperature logs have important applications in the geothermal industry such as the estimation of the static formation temperature (SFT) and the characterization of fluid loss from a borehole. However, the temperature distribution of the wellbore relies on various factors such as wellbore flow conditions, fluid losses, well layout, heat transfer mechanics within the fluid as well as between the wellbore and the surrounding rock formation, etc. In this context, the numerical approach presented in this paper is applied to investigate the influencing parameters/uncertainties in the interpretation of borehole logging data. To this end, synthetic temperature logs representing different well operation conditions were numerically generated using our newly developed wellbore simulator. Our models account for several complex operation scenarios resulting from the requirements of high-enthalpy wells where different flow conditions, such as mud injection with- and without fluid loss and shut-in, occur in the drill string and the annulus. The simulation results reveal that free convective heat transfer plays an important role in the earlier evolution of the shut-in-time temperature; high accuracy SFT estimation is only possible when long-term shut-in measurements are used. Two other simulation scenarios for a well under injection conditions show that applying simple temperature correction methods on the non-shut-in temperature data could lead to large errors for SFT estimation even at very low injection flow rates. Furthermore, the magnitude of the temperature gradient increase depends on the flow rate, the percentage of fluid loss and the lateral heat transfer between the fluid and the rock formation. As indicated by this study, under low fluid losses $(<30 \%)$ or relatively higher flow rates $(>20 \mathrm{~L} / \mathrm{s})$, the impact of flow rate and the lateral heat transfer on the temperature gradient increase can be ignored. These results provide insights on the key factors influencing the well temperature distribution, which are important for the choice of the drilling data to estimate SFT and the design of the inverse modeling scheme in future studies to determine an accurate SFT profile for the high-enthalpy geothermal environment.
\end{abstract}

Keywords: Temperature logs, Static formation temperature, Wellbore simulation, High-temperature well, Horner-plot method, Heat transfer, Fluid loss 


\section{Introduction}

Geothermal explorations depend strongly on reservoir conditions which are evaluated by increasingly sophisticated reservoir simulators (Cacace et al. 2010; O'Sullivan and O'Sullivan 2016; Konrad et al. 2019). Also, data acquisition, mostly of seismic data, has reached a high degree of complexity. This is, however, contrasted by little effort in the evaluation of logging data, especially of temperature logs. Usually, the primary objectives of running a temperature survey in a well are to obtain valuable information on geothermal reservoirs such as the static formation temperatures (SFT) and the location of fluid loss zones. This requires temperature logs measured at different stages (mud circulation and shut-in) during the evolution of the temperature in the borehole fluidformation system as well as different interpretation techniques of these temperature logs (Witterholt and Tixier 1972).

The SFT is usually inferred from the measurement of bottom-hole temperature (BHT) when the drilling circulation has stopped and the borehole fluid temperature gradually develops towards the initial or unperturbed formation temperature. Due to the thermal disturbances caused by the drilling mud, the measured BHT is usually lower than the true SFT and needs to be corrected to obtain a reliable estimate (Deming 1989; Goutorbe et al. 2007). Various temperature correction methods based on different simplified physical models have been developed, e.g., the Horner-plot method [or constant line source method (Bullard 1947; Dowdle and Cobb 1975)]; the spherical and radial heat flow method (Ascencio et al. 1994, 2006); the Hasan-Kabir method (or conductive-convective cylindrical heat source model (Hasan and Kabir 1994) and the Kutasov-Eppelbaum method [or generalized Horner method (Kutasov and Eppelbaum 2005)]. These methods are based on linear or non-linear regression models that describe the relationship between measured BHT and time functions (Verma et al. 2006a, Verma et al. 2006b; Wong-Loya et al. 2012) accounting for the transient effects of thermal recovery during the shut-in phase of the borehole. The simplicities in these methods make them very prevalent engineering tools for estimating SFT.

Another important application of temperature logs is the identification of fluid loss or feed zones from temperature data obtained under hydraulic testing conditions (Okandan 2012; Steingrimsson 2013). Examples of using temperature measurements in boreholes are multifold. Pehme et al. (2010) identified hydraulically active fractures in dolomite and sandstone aquifers; Klepikova et al. (2011) estimated local transmissivities and hydraulic head differences; Nian et al. (2015) predicted flow rates in oil and gas production wells. These authors stressed the satisfactory accuracy of temperature-derived flow velocities compared to direct flow measurement. In recent years, fiber-optic distributed temperate sensing (DTS), which is a robust means of acquiring continuous temperature profiles instantaneously along the length of the cable (Großwig et al. 1996), has also been extensively used to improve the accuracy of flow rate profiling and the detection of fracture zones (Read et al. 2013; Coleman et al. 2015; Read et al. 2015; Bense et al. 2016).

In a high-temperature environment, the acquisition of logging data from exploration and drilling projects in geothermal fields is more challenging compared to its petroleum counterparts. In recent years, high-temperature geothermal systems have gained attention due to their large potential for energy extraction. In fact, a number of wells drilled in geothermal fields such as The Geysers (USA), Los Humeros (Mexico), Kakkonda (Japan), Larderello 
(Italy), and Reykjanes (Iceland) have been reported (Reinsch et al. 2017; Kruszewski and Wittig 2018) to even reach supercritical conditions for water $\left(T>374{ }^{\circ} \mathrm{C}, P>221\right.$ bar). Reliable logging in such extreme well conditions is currently very challenging using conventional tools, which are normally rated up to $175{ }^{\circ} \mathrm{C}$ bottom-hole temperature (Baird et al. 1993). Although high temperature and pressure logging tools are available (Ikeuchi et al. 1998; Sekine et al. 2004; Reinsch et al. 2013), these tools are generally all restricted to specific operating conditions in harsh environments. For example, the electronic Kuster K10, a commonly used commercial tool in the industry, can operate at a maximum of $350{ }^{\circ} \mathrm{C}$ only up to $4 \mathrm{~h}$ (Danielsen 2008). This short period may be sufficient for the tripping of the logging tools but not for collecting data to resolve the transient thermal response under shut-in condition. DTS, which is considered better suited for use at elevated temperatures, gives erroneous temperature readings under high temperatures $\left(>300^{\circ} \mathrm{C}\right)$ due to the chemical and thermal degradation of the optical fiber (Reinsch et al. 2013; Laarossi et al. 2019). To keep the temperature of the measuring device below its maximum tolerance, cooling through continuous injection during logging is necessary for extreme high-temperature boreholes (Friðleifsson et al. 2018).

The present study focuses on the analysis of temperature logging data from high-temperature geothermal wells. It particularly addresses the specific conditions (e.g., drill pipe-andannulus geometry and continuous injection) which result from the requirements of such an environment. Two sets of simulation examples are analyzed to reflect possible logging conditions in a high-enthalpy well. In the first example, fluid injection followed by shut-in is simulated. This example is used to examine the validity of applying simple BHT correction methods on the shut-in temperature data to estimate SFT, as well as to evaluate the impact of the free convection heat transfer in the build-up of borehole fluid temperature and the SFT estimation results. To the authors' knowledge, the latter was hardly discussed in former wellbore simulation studies (Espinosa-Paredes et al. 2009; Yang et al. 2015). The second example investigates two new topics for high-temperature geothermal wells underinjection. One scope of the investigation is whether simple BHT type correction methods are still applicable to logging data from boreholes which are under continuous cooling due to the restriction of the logging tool. Furthermore, a new method is discussed to quantify the fluid loss percentage from temperature logs by computing the ratio of temperature gradient below and above the fluid loss point.

\section{Methods}

\section{Analytical approach to estimate SFT-Horner-plot method}

Herein, the Horner-plot method (HM) for SFT estimation using shut-in temperature logs is analyzed. This method was selected due to its wide application in the geothermal industry (Andaverde et al. 2005; Kutasov and Eppelbaum 2018). The evaluations of other SFT estimation methods fall outside the scope of this paper but can be achieved similarly. The HM approximates the thermal effect of the drilling as an infinitely thin and long axial heat source extracting heat at a constant rate and, therefore, perfect conducting conditions in the well are assumed. The mathematical form of the HM is simplified as follows:

$$
T_{s}=T_{i}+\frac{q}{4 \pi \lambda_{s}} \ln \frac{t_{c}+t_{s}}{t_{s}}
$$


where $T_{s}$ is the borehole shut-in temperature, $T_{i}$ is the SFT, $t_{s}$ is the shut-in time, $t_{c}$ is the circulation time, $q$ is the heat extraction rate. According to Eq. 1, a semi-logarithmic plot of $T_{s}$ against the Horner dimensionless time $\left(t_{c}+t_{s}\right) / t_{s}$ should be a straight line intercepting with the vertical axis at $T_{i}$. The standard procedure of applying the Horner-plot method has been to extrapolate this line until $t_{s} \rightarrow \infty$ (Horner dimensionless time $=1$ ) with the intercept yielding the SFT value.

\section{Numerical approach}

An in-house numerical simulation tool is used to model the thermal behavior of the wellbore and its surrounding formation. The simulator is an application developed based on the MOOSE framework which provides a multiphysics object-oriented simulation environment (Gaston et al. 2009). MOOSE allows for efficient utilization of a wide range of computational hardware using both shared-memory and distributed-memory parallelism (Permann et al. 2013). The MOOSE-based application consists of different physics modules which can be easily added, removed and coupled for solving variables in an implicit and fully coupled manner.

Figure 1 shows the schematic of typical wellbore flow and heat transfer scenarios. The cold drill fluid is considered to be either injected both in through the drill pipe and the annulus (coflow); or injected in the drill pipe and circulated back to the surface (counterflow). The simulator assumes the wellbore to be treated either as a onedimensional or a two-dimensional structure depending on the problem being studied. When a two-dimensional wellbore structure is considered, the wellbore components, such as the fluid inside the drill pipe, the drill pipe wall, the annulus, and the casings,

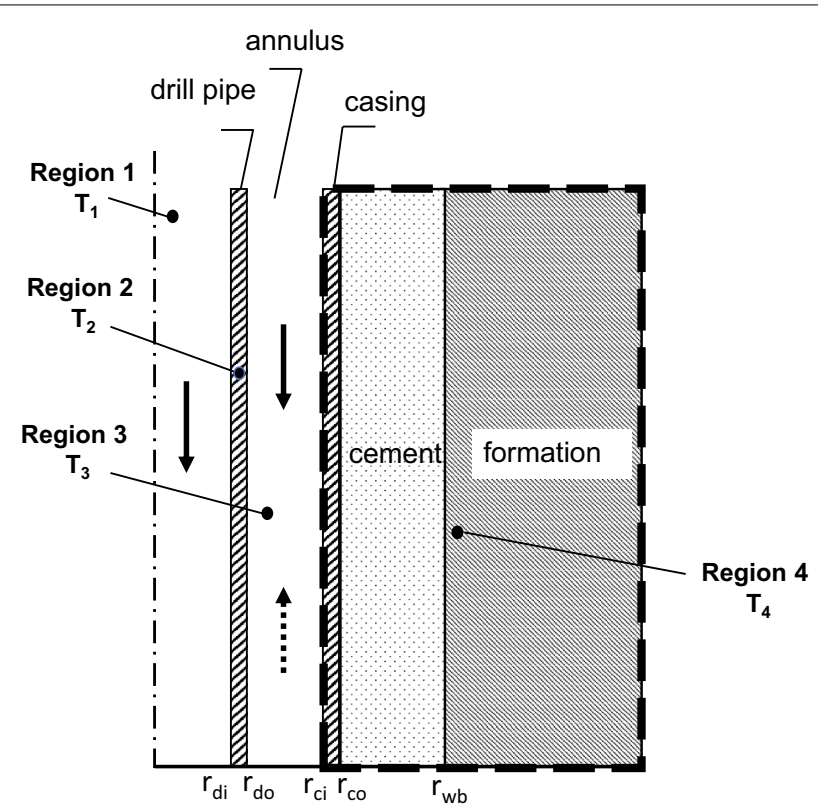

Fig. 1 Schematic of the heat exchange model between the wellbore and the formation. Governing equations are solved in four regions: the fluid inside the drill pipe (region 1), the drill pipe wall (region 2), the annulus (region 3), casing-cement-formation (Region 4). The solid arrow pointing downwards and the dashed arrow pointing upwards in the annulus refer to coflow and counterflow scenarios in the wellbore, respectively 
are treated as different regions (region $1,2,3,4$, respectively) in which the temperatures $\left(T_{1}, T_{2}, T_{3}\right.$, and $\left.T_{4}\right)$ need to be solved as individual variables (Fig. 1). These variables are linked through the interfacial heat transfer relationships between the fluid and the solid. The injection fluid was assumed to be pure liquid water. Fluid properties such as density, viscosity, and heat capacity were calculated according to the IAPWS-IF97 formulation (Cooper and Dooley 2007). The fundamental assumptions of the models considered in this work are: the geometries of the wellbore and formation are cylindrical, the fluid is incompressible, fluid flow is in the axial direction only, the rock formation is impermeable, there is no radial temperature gradient within the fluid when the wellbore is considered to be a two-dimensional structure, thermal dissipation and expansion effects are negligible.

Making these assumptions, the energy conservation equation for the fluid inside the drill pipe and annulus is written in the following form:

$$
\rho_{f} C_{p, f}\left(\frac{\partial T_{f}}{\partial t}+v_{r, f} \frac{\partial T_{f}}{\partial r}+v_{z, f} \frac{\partial T_{f}}{\partial z}\right)-\frac{\lambda_{f}}{r} \frac{\partial T_{f}}{\partial r}-\lambda_{f} \frac{\partial^{2} T_{f}}{\partial^{2} r}-\lambda_{f} \frac{\partial^{2} T_{f}}{\partial^{2} z}=0
$$

The continuity equation for incompressible flow is given by:

$$
\frac{1}{r} \frac{\partial\left(r v_{r, f}\right)}{\partial r}+\frac{\partial v_{z, f}}{\partial z}=0
$$

where $\rho_{f}$ is the fluid density, $C_{p, f}$ is the fluid specific heat capacity, $v_{z}$ and $v_{r}$ are the axial and radial flow velocities, respectively, $\lambda_{f}$ is the thermal conductivity.

The energy conservation equation for the pipe wall, casing and formation can be expressed as:

$$
\rho_{s} C_{p, s} \frac{\partial T_{s}}{\partial t}-\frac{\lambda_{s}}{r} \frac{\partial T_{s}}{\partial r}-\lambda_{s} \frac{\partial^{2} T_{s}}{\partial^{2} r}-\lambda_{s} \frac{\partial^{2} T_{s}}{\partial^{2} z}=0,
$$

where $\rho_{s}, C_{p, s}, \lambda_{s}$ is the density, heat capacity and thermal conductivity of the pipe wall, casing and formation, respectively.

The final forms of the above governing equations for regions 1, 2, 3, 4 (Fig. 1) are simplified into:

$$
\begin{aligned}
& \frac{\partial v_{z_{i}}}{\partial z}=0, \quad i=1,3 \\
& \rho C_{p}\left(\frac{\partial T_{i}}{\partial t}+v_{z_{i}} \frac{\partial T_{i}}{\partial z}\right)-\frac{\lambda}{r} \frac{\partial T_{i}}{\partial r}-\lambda \frac{\partial^{2} T_{i}}{\partial^{2} r}-\lambda \frac{\partial^{2} T_{i}}{\partial^{2} z}=0, \quad i=1,3 \\
& \rho C_{p} \frac{\partial T_{i}}{\partial t}-\frac{\lambda}{r} \frac{\partial T_{i}}{\partial r}-\lambda \frac{\partial^{2} T_{i}}{\partial^{2} r}-\lambda \frac{\partial^{2} T_{i}}{\partial^{2} z}=0, \quad i=2,4
\end{aligned}
$$

where $i$ refers to the region number.

The initial and boundary conditions of the thermal-hydraulic models considered in this work are given in Table 1. The validation of the numerical tool is done by comparing the numerical simulation results and analytical solutions of Ramey's wellbore 
Table 1 Boundary and initial conditions of the thermal-hydraulic models

\begin{tabular}{|c|c|c|}
\hline BC and IC & Expression & Description \\
\hline IC & $\begin{array}{l}T_{i}(r, z, t=0)=T_{f}(r, z), i=1,2,3,4 \\
\quad \forall r, 0 \leq z \leq H\end{array}$ & $\begin{array}{l}\text { The initial temperature is equal to the formation } \\
\text { temperature }\end{array}$ \\
\hline$B C 1$ & $v_{z_{i}}=\frac{\dot{m}_{i}}{\rho A_{i}}, z=0, i=1,3$ & $\begin{array}{l}\text { The velocity of the drill pipe fluid and the annulus } \\
\text { fluid is calculated according to the mass flow rate at } \\
\text { the wellhead }\end{array}$ \\
\hline $\mathrm{BC} 2$ & $q=-\left.\lambda\left(\frac{\partial T}{\partial r}\right)\right|_{\Gamma_{i j}}=h\left(T_{i}-T_{j}\right)$, on $\Gamma_{12}, \Gamma_{23} \Gamma_{34}$ & $\begin{array}{l}\text { Heat flux across the solid-fluid interface is deter- } \\
\text { mined by the heat transfer coefficient times the } \\
\text { temperature difference between fluid and solid wall }\end{array}$ \\
\hline $\mathrm{BC} 3$ & $-\lambda\left(\frac{\partial T_{1}}{\partial r}\right)=0$ at $z=H, z=0$ & $\begin{array}{l}\text { No thermal gradient at the surface and bottom of the } \\
\text { reservoir }\end{array}$ \\
\hline BC4 & $T_{4}(r=\infty, z, t)=T_{f}(r, z)$ at $r=\infty$ & $\begin{array}{l}\text { Formation temperature at the far-field remains } \\
\text { undisturbed }\end{array}$ \\
\hline BC5 & $T_{1}(r, z=0, t)=T_{\text {inj }}$ at $0<r<r_{1}, z=0$ & $\begin{array}{l}\text { The temperature at the well-head equals the injection } \\
\text { temperature }\end{array}$ \\
\hline BC6 & $T_{1}(z=H, t)=T_{3}(z=H, t)$ & $\begin{array}{l}\text { The fluid temperature of the drill pipe fluid and the } \\
\text { annulus fluid at the bottom hole is equal. This is } \\
\text { only validated for the counterflow scenario (mud } \\
\text { circulation) }\end{array}$ \\
\hline
\end{tabular}

$A_{i}$ is the flow cross-section, $\Gamma_{i j}$ is the interfacial area between the fluid and solid structures, e.g., drill pipe, casing and formation, $\mathrm{H}$ is the well depth, $T_{f}(r, z)$ is the formation temperature, $T_{\mathrm{inj}}$ is the injection temperature of the fluid, $h$ is the heat transfer coefficient

heat transmission model (Ramey 1962, Ramey 1964) (Appendix A) and the counterflow heat exchange model (Bobok and Szarka 2012) (Appendix B).

\section{Heat transfer coefficients}

As mentioned above, the thermal exchange between different wellbore regions is modeled via thermal transfer relations at their interfaces (Table 1, BC2). The heat transfer coefficient, $h$, is the proportionality constant between the heat flux and the thermodynamic driving force for the heat flow (i.e., the temperature difference between adjacent wellbore components, $\Delta T$ ). In this work, the heat transfer coefficients under forced convection and shut-in condition are correlated and calculated using different approaches.

\section{Forced convection}

Under forced convection, the heat transfer coefficient is defined as (Yang et al. 2015):

$$
h=\frac{\mathrm{Nu} \cdot \lambda_{f}}{d}
$$

where $\mathrm{Nu}$ is the Nusselt number, $d$ is the hydraulic diameter of the drill pipe and annulus.

For laminar flow inside the annulus, $\mathrm{Nu}$ is calculated using the Sieder-Tate correlation (Kohl et al. 2002):

$$
\mathrm{Nu}=1.86(\operatorname{Re} \operatorname{Pr})^{1 / 3}\left(\frac{d}{L}\right)^{1 / 3}\left(\frac{\mu}{\mu_{w}}\right)^{0.14}, \quad \operatorname{Re} \leq 2300,
$$

where $L$ is the length of the tube, Pr is the Prandtl number, $\mu$ is the dynamic viscosity of the bulk fluid, $\mu_{\mathrm{w}}$ is the fluid viscosity at the temperature of the tube wall. 
In the laminar regime inside the drill string

$$
\mathrm{Nu}=4.364, \quad \text { for } \quad \mathrm{Re} \leq 2300
$$

For highly turbulent flow, the Dittus-Boelter equation (Dittus and Boelter 1985) is applied:

$$
N u=0.023 \cdot \operatorname{Re}^{0.8} \cdot \operatorname{Pr}^{0.3}, \quad \text { for } \quad \operatorname{Re} \geq 1 e 4 .
$$

For the transition between laminar and highly turbulent flow, the Nusselt number is estimated by the following linear interpolation (Diersch et al. 2011; Gnielinski 2013):

$$
\mathrm{Nu}=(1-\gamma) \cdot 4.364+\gamma \cdot 0.023 \cdot \operatorname{Re}^{0.8} \cdot \operatorname{Pr}^{0.3}, \quad \text { for } \quad 2300<\operatorname{Re}<1 e 4
$$

with

$$
\gamma=\frac{\operatorname{Re}-2300}{10^{4}-2300}
$$

\section{Shut-in condition}

So far in most theoretical and simulation studies, pure conductive heat flow in a static water column is assumed when estimating temperature recovery during borehole shutin (Shen and Beck 1986; García et al. 1998; Espinosa-Paredes et al. 2001; Yang et al. 2015). The heat transfer coefficient in the borehole fluid is then approximated by:

$$
h_{c}=\frac{\lambda_{f}}{r_{\mathrm{wb}}},
$$

where $r_{\mathrm{wb}}$ is the borehole radius.

However, several studies have reported the existence of another key factor in the heat transfer, which is free convection caused by density differences arising from vertical temperature gradients (Diment 1967; Gretener 1967; Pfister and Rybach 1995; Berthold and Börner 2008; Eppelbaum and Kutasov 2011; Klepikova et al. 2018). The critical parameters for the free convection process can be indicated by the following equation (Diment and Urban 1983):

$$
\nabla T_{\mathrm{cr}}=\frac{g \cdot \alpha \cdot T_{\mathrm{abs}}}{c_{p}}+\frac{C \cdot v \cdot D_{T}}{g \cdot \alpha \cdot r_{\mathrm{wb}}^{4}},
$$

where $\nabla T_{\text {cr }}$ is the critical thermal gradient to initiate free convection, $g$ is the acceleration due to gravity, $\alpha$ is the thermal expansion coefficient, $T_{\text {abs }}$ is the absolute temperature $(K), C_{p}$ is the specific heat capacity, $C$ is a constant with a value of 216 for tubes, $v$ is the fluid kinematic viscosity, $D_{\mathrm{T}}$ is the fluid thermal diffusivity. Taking the following values as typical for the borehole fluid: $v=1 \mathrm{e}-6 \mathrm{~m}^{2} / \mathrm{s}, \alpha=2 \mathrm{e}-4 \mathrm{~K}^{-1}, D_{\mathrm{T}}=1.4306 \mathrm{e}-7 \mathrm{~m}^{2} / \mathrm{s}$, $c_{p}=4149 \mathrm{~J} /(\mathrm{kg} \mathrm{K})$, absolute temperature range of $273.15-573.15 \mathrm{~K}$. This equation reveals that for a borehole with a radius of $35-150 \mathrm{~mm}$, the average critical thermal gradient needed to initiate free convection is $2.36 \mathrm{e}-4$ to $1 \mathrm{e}-2 \mathrm{~K} / \mathrm{m}$.

Unlike forced convection, which normally acts only in the axial direction, free convection enhances the heat transfer in all directions through fluid circulation and mixing. However, a well-established quantitative description of the thermal effect of free 
convection in boreholes is still missing, and a general modeling approach is not available. Luheshi (1983) showed that free convection does not significantly enhance vertical heat transfer. Since the radial temperature gradient is typically much larger, the contribution to heat flux in the vertical direction by free convection is considered negligible. However, he mentioned it might be necessary to account for the enhancement in radial heat flux due to the mixing effect of fluid motion induced by buoyancy forces. In our work, we have assumed the increase of the heat transfer rate due to free convection only acts in the radial direction. The overall heat transfer coefficient can be written as:

$$
h=h_{c}+h_{\text {free }},
$$

which means that the heat transfer for the shut-in condition results from conduction and free convection.

In our models, the heat transfer coefficient for forced convection was calculated explicitly according to Eqs. (8)-(13). While for the shut-in condition, the heat transfer due to free convection was either neglected $\left(h_{\text {free }}=0\right)$ or was implicitly evaluated (e.g. $h_{\text {free }}$ is a factor or fraction of $h_{\mathrm{c}}$ ).

\section{Simulation scenarios}

In the simulation studies, we began with the application of HM to the simulated shut-in temperature logs. Then we simulated two logging scenarios in a high-temperature environment. In one scenario, temperature logs obtained under continuous borehole cooling were used to estimate SFT and the sensitivity of the estimation error to different flow rates was investigated. In another scenario, temperature logs were used to quantify the fluid loss in the well.

\section{Shut-in temperature logs simulation}

The evaluation of the HM was conducted by numerical simulation of both the circulation and shut-in stage of well operation. In this model, fluid flow in a straight, non-cased two-dimensional well embedded in the two-dimensional formation was considered. The modeling parameters can be found in Table 2. The model domain size of $2500 \mathrm{~m}$ in the axial direction and $50 \mathrm{~m}$ in the radial direction was chosen to reflect the reservoir depth and to ensure that the lateral outer boundary represents far-field conditions which were not affected by thermal perturbations from well operations. The FE mesh was discretized with 150 layers in the axial direction $(\Delta z=16.7 \mathrm{~m})$. In the radial direction, the mesh was refined near the well $\left(\Delta r_{\min }=10^{-3} \mathrm{~m}\right)$ and coarsened at a larger lateral distance $\left(\Delta r_{\max }=4 \mathrm{~m}\right)$. The final mesh size was determined by performing a sensitivity analysis yielding asymptotic smaller variations for the calculated temperatures (maximum temperature variations of less than $10^{-2}{ }^{\circ} \mathrm{C}$ ). The procedure mentioned above for determining the model domain, mesh sizes, etc., has been applied analogously to each of the models in this work.

The total simulation time was 150 days with 10 days being the cooling (injection) period followed by the shut-in period. The numerically predicted temperatures of borehole fluid during shut-in were used to estimate the SFT according to Eq. 1. The rate of heat transfer during the shut-in period was controlled by the magnitude of the heat transfer coefficient in the model. To investigate the impact of free convection on the 
Table 2 Geometry and material properties used in the modeling of circulation and shut-in

\begin{tabular}{lll}
\hline Property & Unit & Value \\
\hline Formation temperature at the surface & ${ }^{\circ} \mathrm{C}$ & 20 \\
Bottom-hole temperature & ${ }^{\circ} \mathrm{C}$ & 245 \\
Formation rock density & $\mathrm{kg} / \mathrm{m}^{3}$ & 2650 \\
Formation thermal conductivity & $\mathrm{W} /\left(\mathrm{m}{ }^{\circ} \mathrm{C}\right)$ & 2.92 \\
Formation specific heat capacity & $\mathrm{J} /\left(\mathrm{kg}{ }^{\circ} \mathrm{C}\right)$ & 1000 \\
Well depth & $\mathrm{m}$ & 2500 \\
Well radius & $\mathrm{m}$ & 0.15 \\
Water injection rate $\left(Q_{\text {inj }}\right)$ & $\mathrm{kg} / \mathrm{s}$ & 20 (first 10 days); \\
& & 0 (after \\
Water injection temperature $\left(T_{\text {inj }}\right)$ & ${ }^{\circ} \mathrm{C}$ & 10 days) \\
The geothermal gradient & ${ }^{\circ} \mathrm{C} / \mathrm{m}$ & 20 \\
Water specific heat capacity & $\mathrm{J} /\left(\mathrm{kg}{ }^{\circ} \mathrm{C}\right)$ & 0.09 \\
Water thermal conductivity & $\mathrm{W} /\left(\mathrm{m}{ }^{\circ} \mathrm{C}\right)$ & 3160 \\
\hline
\end{tabular}

temperature recovery during shut-in, we considered different values of $h_{\text {free }}: 0, h_{c}, 9 h_{c}, \infty$. According to Eq. (16), the heat transfer coefficients then became: (1) $h=h_{c}$; (2) $h=2 h_{c}$; (3) $h=10 h_{c}$; (4) $h=\infty$. Case (4) corresponds to the condition where the fluid acts as a perfect conductor and thermal resistance in the well does not exist.

\section{High-temperature environment simulation}

In this section, we focus on the simulation of temperature logs in a high-temperature environment. For this purpose, we have assumed the SFT to be in a temperature range from $5{ }^{\circ} \mathrm{C}$ (surface) to $500{ }^{\circ} \mathrm{C}$ (bottom-hole). Two different SFT profiles were analyzed. The profile was either linear-shaped which could be linked to a geothermal system controlled by pure heat conduction, or S-shaped representing commonly observed heat convection zones (Fig. 2). The wellbore layout included the drill pipe, annulus and several casings (Table 3). The above-described SFT profiles and wellbore layout were used in each of the following simulation cases.

\section{Continuous borehole cooling}

The simulations assumed that cold water $\left(7^{\circ} \mathrm{C}\right)$ was injected for 10 days both into the drill pipe and into the annulus at a flow rate of $15 \mathrm{~L} / \mathrm{s}$ and $45 \mathrm{~L} / \mathrm{s}$, respectively (first period). In the second period (thermal recovery), injection into the drill pipe stopped while annulus injection continued but the flow rate was reduced to $Q$ ( $Q$ ranged between 0 and $5 \mathrm{~L} / \mathrm{s}$ ). The borehole was under the full shut-in condition when $Q$ was $0 \mathrm{~L} / \mathrm{s}$; otherwise, it was under partial shut-in condition. Temperatures of the fluid inside the drill pipe at different warm-up times were measured and then used to estimate SFT by applying the HM.

\section{Fluid loss}

The impact of fluid loss on the temperature response in a borehole is analyzed by generating a series of dynamic temperature logs based on forward simulations where different fluid loss amounts under different flow rates in the borehole were assumed. These 


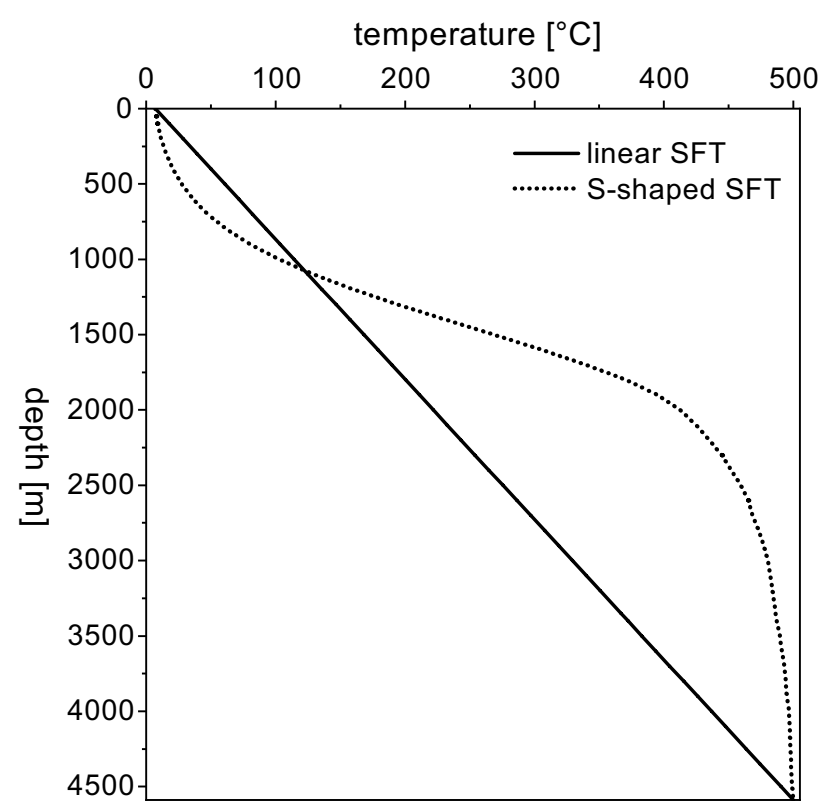

Fig. 2 Two different SFT profiles assumed in the high-temperature environment simulations: linear SFT describes a pure heat conduction geothermal system, S-shaped SFT reflects typically occurring convection zones in the geothermal system

Table 3 Geometrical extensions of the wellbore

\begin{tabular}{lllll}
\hline & Inner radius $(\mathbf{m})$ & Outer radius $(\mathbf{m})$ & $\begin{array}{l}\text { Cross-sectional area } \\
\left(\mathbf{m}^{\mathbf{2}}\right)\end{array}$ & Depth $(\mathbf{m})$ \\
\hline Drill pipe & 0.0352 & & $2.33 \times 10^{-03}$ & $0-4589$ \\
Casing i & 0.0797 & 0.0445 & $4.87 \times 10^{-03}$ & $0-1304$ \\
Casing ii & 0.11 & 0.0889 & $8.75 \times 10^{-03}$ & $0-2941$ \\
Casing iii & 0.1577 & 0.122 & $1.26 \times 10^{-03}$ & $0-793$ \\
Annulus & 0.0445 & 0.1699 & $1.37 \times 10^{-02}$ & $0-1304$ \\
& 0.0445 & 0.0797 & $3.18 \times 10^{-02}$ & $1304-4589$ \\
\hline
\end{tabular}

temperature logs were used as samples for the analysis of the temperature response to the fluid loss in the borehole.

Again cold water $\left(7^{\circ} \mathrm{C}\right)$ was injected through the drill pipe and the annulus separately, and the temperature logs were only 'recorded' in the drill pipe. For simplicity, the total amount of fluid being injected was distributed such that the flow velocities in the string and the annulus were equal. The fluid loss occurred at $3.35 \mathrm{~km}$ depth from the annulus through a hydraulic connection to the formation. The total amount of injected fluid was varied from 5 to $50 \mathrm{~L} / \mathrm{s}$. The percentage of fluid loss from the annulus was varied between 0 and $100 \%$.

\section{Results and discussion}

\section{Estimating SFT using shut-in temperature logs}

The evolutions of BHT with respect to time considering four different heat transfer rates are given in Fig. 3a. It is shown that the recovery of BHT is influenced by 


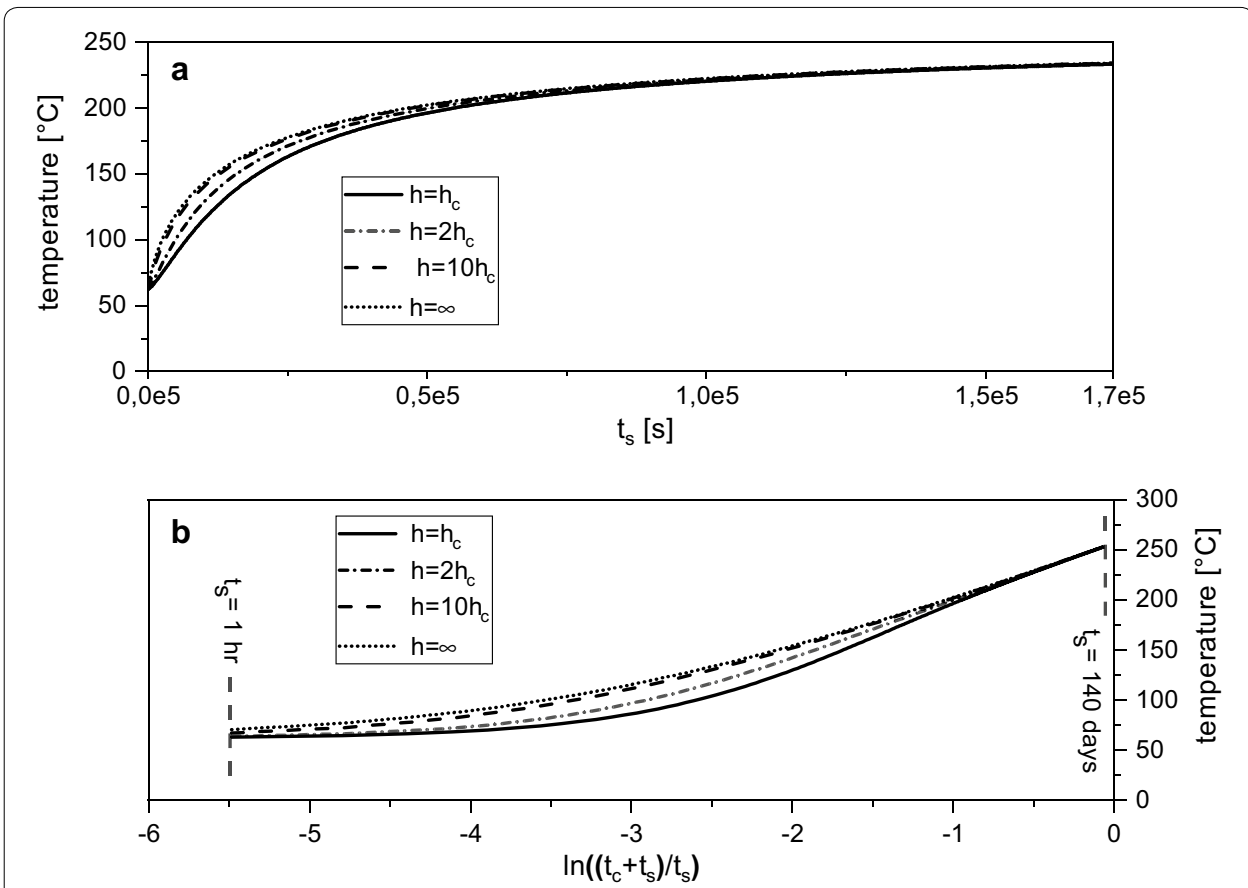

Fig. 3 a The change of BHT within a shut-in period of 20 days under four different heat transfer coefficients (h) in the borehole. $\mathbf{b}$ The Horner-plots of the four temperature curves shown in $\mathbf{a}$ [the $x$-axis value is the opposite of the Horner dimensionless time (Eq. 1), the minimum $x$-axis value of the temperature data on the curves corresponds to when $t_{s}=1 \mathrm{~h}$, the maximum $x$-axis value corresponds to when $t_{s}=140$ days]

the heat transfer rate in the borehole during the early stage of shut-in. The higher the heat transfer rate is, the faster the temperature builds up. A maximum difference of $30^{\circ} \mathrm{C}$ between the predicted BHTs is found. However, the four temperature curves have approximately the same build-up rate after 20 days. Furthermore, the sensitivity of temperature build-up on the heat transfer rate decreases when the heat transfer rate reaches $10 h_{c}$. Figure $3 \mathrm{~b}$ shows the plots of the BHT against the Horner dimensionless time. For each curve, two different BHT data sets are used to estimate the SFT. One contains the early shut-in-time temperature data measured within 1 day $\left(t_{s}=12,18,24 \mathrm{~h}\right)$; another one contains long-term shut-in measurements of several days $\left(t_{s}=2,3,4\right.$ days). The regression lines for the early and the long-term shut-in BHT measurements are plotted in Fig. 4a, b, respectively. Figure 4c displays the comparison between the intercepts of these regression lines (SFT estimates) and the true SFT value. In all cases, the SFT is underestimated with a large error when early shut-in-time temperature data are used. The underestimation errors range from -61.9 to $-31.3{ }^{\circ} \mathrm{C}$ depending on the rate of heat transfer rate assumed in the model. On the other hand, the accuracy for SFT estimation is improved when using long-term shut-in temperature data, and again, the influence of the heat transfer rate on SFT estimation is observed. The SFT tends to be overestimated under low heat transfer rates $\left(h=h_{c}, 2 h_{c}\right)$ and underestimated under higher heat transfer rates $\left(h=10 h_{c}, \infty\right)$. 

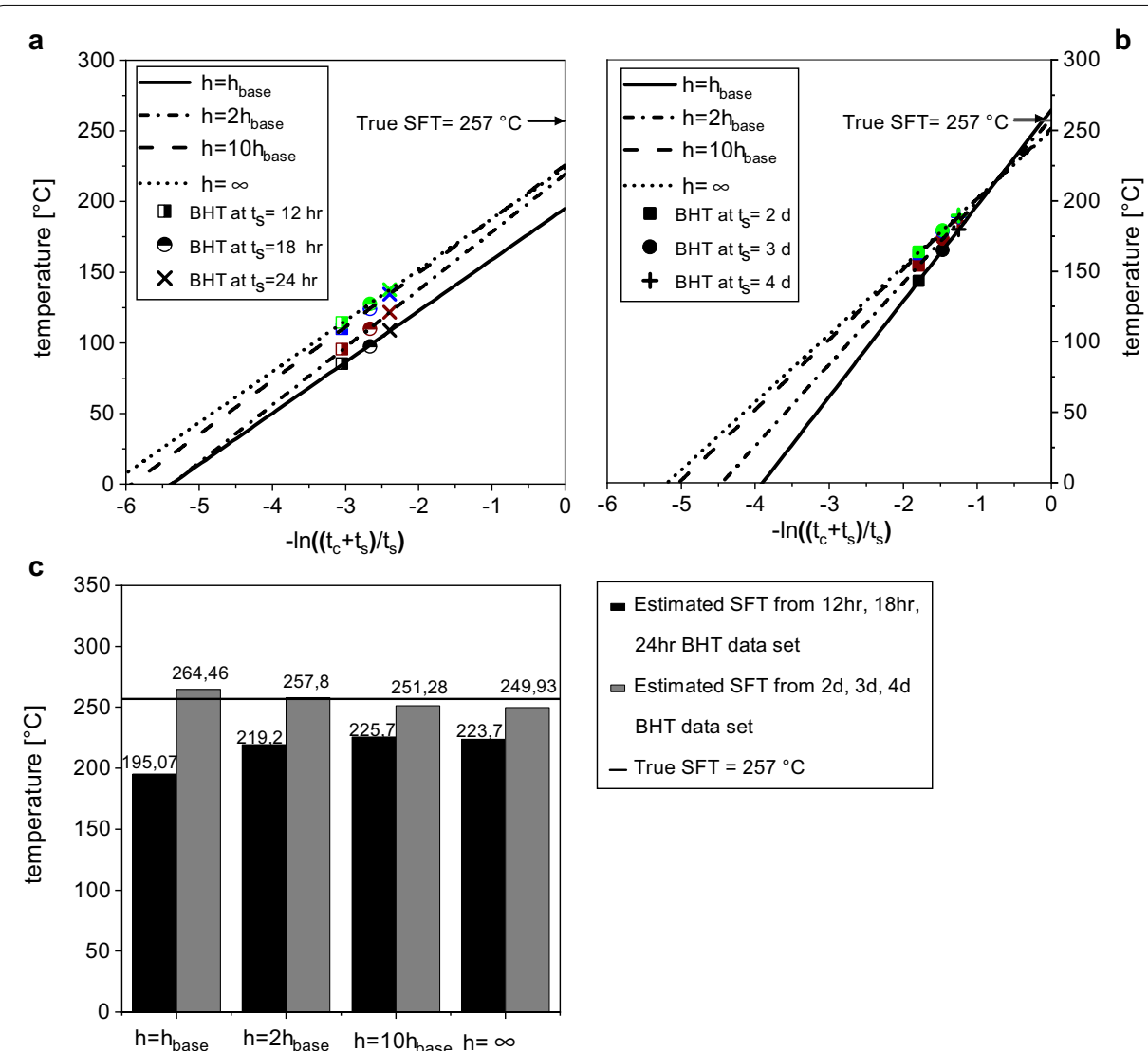

- Estimated SFT from $12 \mathrm{hr}, 18 \mathrm{hr}$,
$24 \mathrm{hr}$ BHT data set
Estimated SFT from $2 \mathrm{~d}, 3 \mathrm{~d}, 4 \mathrm{~d}$
BHT data set
- True SFT $=257^{\circ} \mathrm{C}$

Fig. 4 The HM plots (lines) using BHT measurements (markers) at a early shut-in time ( $t_{s}=12,18$ and $24 \mathrm{~h}$ ) and $\mathbf{b}$ long-term shut-in ( $t_{s}=2,3$, and 4 days) for each of the four different heat transfer coefficients $(h)$ considered. c Comparison of the results of SFT estimation with the true SFT value: the black bars are the four SFT estimates using early shut-in time BHT data; the dark grey bars represent the four SFT estimates using long-term shut-in BHT data; the solid line stands for the referencing value which is the true SFT $\left(257^{\circ} \mathrm{C}\right.$ )

\section{Estimating SFT using temperature logs obtained under borehole cooling}

As shown earlier, both the heat transfer rate in the borehole and the measurement time have an impact on the final result of the estimated SFT. In the following SFT calculations, long-term shut-in temperature data measured after 1 day, 2 days and 3 days since the start of the second period were used. The heat transfer coefficient $h$ for the full shutin conditions was then calibrated by trial and error until an accurate SFT estimation was achieved (see Fig. 5, shut-in case). The calibrated $h$ was examined to be $1.4 h_{c}$ (the SFT estimation error at the bottom-hole was $0.15^{\circ} \mathrm{C}$ for the linear SFT profile scenario, and $0.24{ }^{\circ} \mathrm{C}$ for the S-shaped SFT profile scenario) and it was used to account for the heat transfer rate within the drill pipe in the second period. In the annulus, forced convection heat transfer dominates the heat transfer process. The SFT was estimated assuming different annulus flow rates and the estimation error at bottom-hole was calculated (Fig. 5). As expected, the SFT was underestimated when temperature measurements under cooling conditions were used in all cases. This is because with continuous cold injection in the annulus during the second period, the temperature was only partially recovered in the borehole compared to the shut-in condition. The higher the flow rate in the annulus was, the less the heat would recover and the larger the resulting underestimation error 


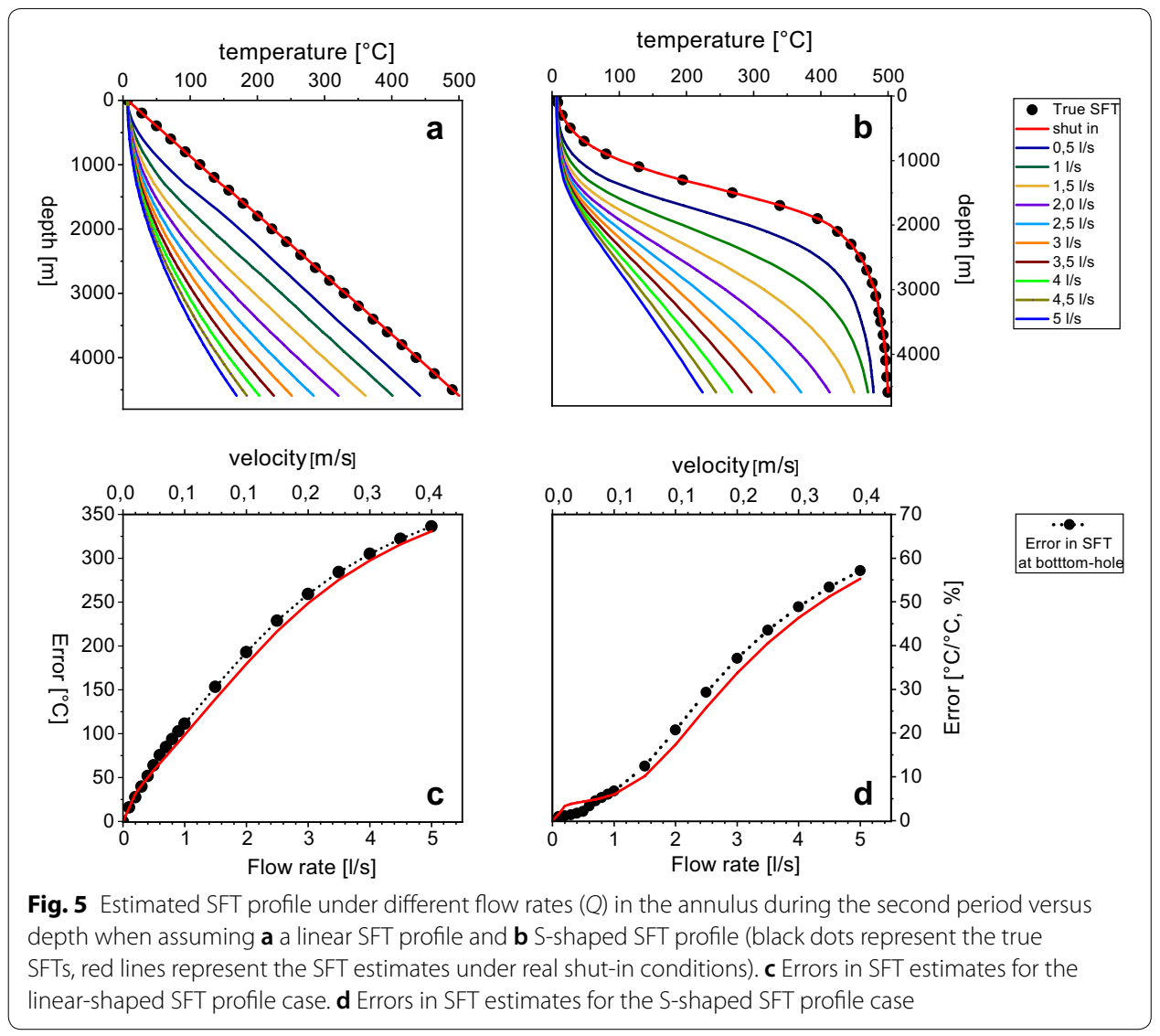

in the SFT (Fig. 5c, d). For small values of flow rate in the annulus up to $0.7 \mathrm{~L} / \mathrm{s}$ (corresponding fluid velocity of $0.05 \mathrm{~m} / \mathrm{s}$ at the bottom-hole), the maximum estimation error at the bottom-hole was around $74{ }^{\circ} \mathrm{C}$ (percentage error 14.8\%) when the linear SFT profile was assumed and $24{ }^{\circ} \mathrm{C}$ (percentage error $4.8 \%$ ) for the S-shaped SFT profile. The reason for the smaller estimation error for the S-shaped profile is the higher SFT value along most parts of the well. Therefore, the fluid is less cooled, resulting in earlier thermal recovery. However, it is noticed that the maximum SFT estimation error along the well depth could be in some cases much greater than the error at the borehole bottom (Fig. 5b, maximum underestimation error of $143{ }^{\circ} \mathrm{C}$ was found at $1800 \mathrm{~m}$ depth for the flow rate of $0.5 \mathrm{~L} / \mathrm{s}$ in the annulus).

\section{Characterization of the fluid loss in the well}

Herein, we present exemplary simulated temperature logs under flow rates of $5 \mathrm{~L} / \mathrm{s}$ and $50 \mathrm{~L} / \mathrm{s}$ for an S-shaped SFT profile (Fig. 6). The results for the linear SFT profile were omitted since it was observed that the shape of the SFT profile had a negligible influence on the temperature response to fluid loss. An abrupt increase in the vertical temperature gradient below the loss zone at $3.35 \mathrm{~km}$ depth is detected in each temperature log. It is also noticed that the relationship between the increase of the temperature gradient and the percentage of fluid loss is not monotonic. On the one hand, when the percentage of fluid loss is below 95\%, a steeper temperature 


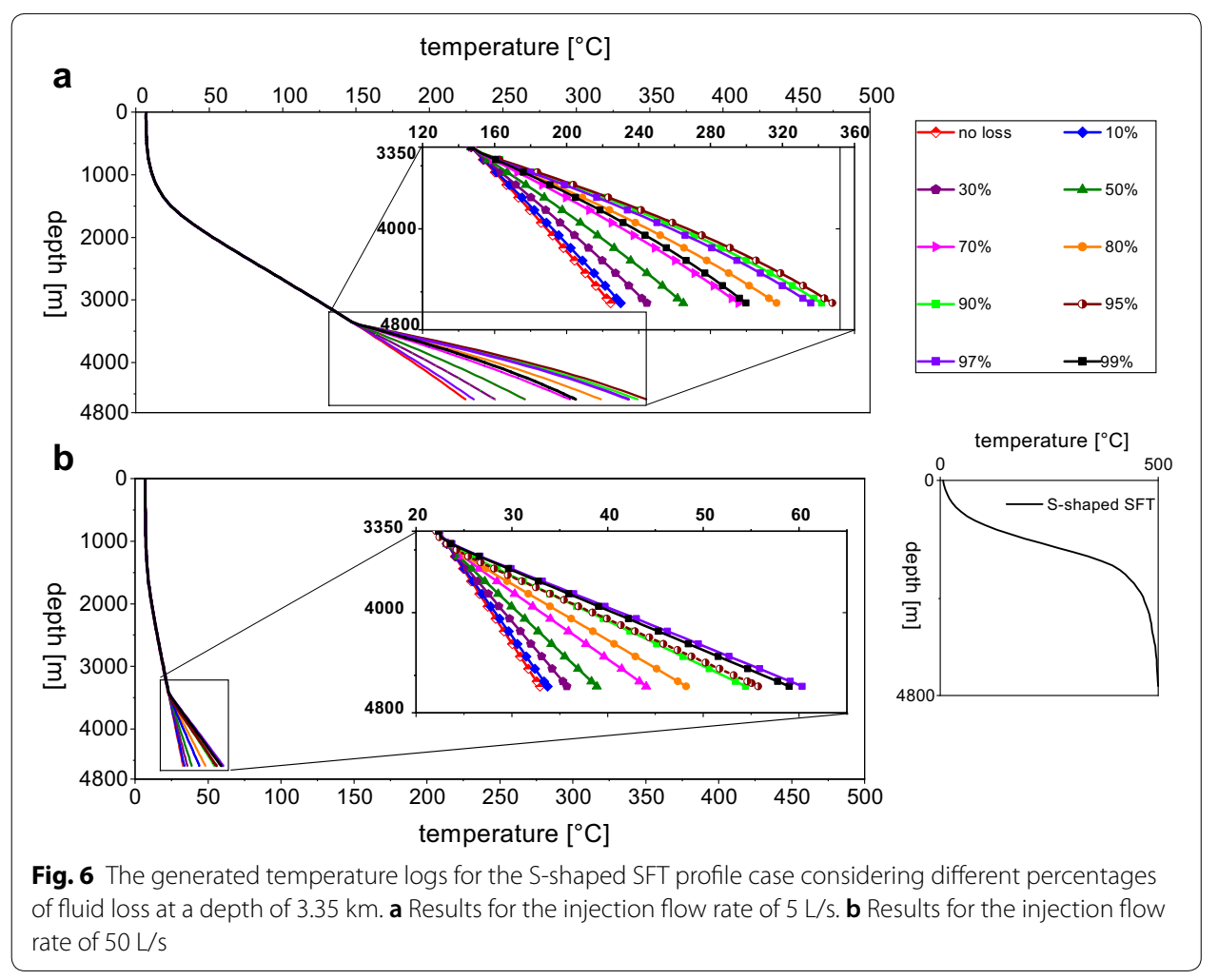

gradient indicates a higher amount of fluid loss in the borehole. Such behavior can be explained by the fact that with more fluid being lost from the annulus, the fluid remaining in the borehole has more residence time to gain heat from the hotter surroundings and thereby the fluid temperature tends to increase. On the other hand, the increase in the temperature gradient drops when the fluid is almost completely lost. This is due to the fact that very high fluid losses cause very low remaining flow rates. As a result, the heat transfer rate from the formation to the annulus fluid is also strongly impaired. The reduced heat flux results in lower fluid temperatures both in the annulus and drill pipe.

We performed further analyses by calculating the increase of the vertical temperature gradient due to the presence of fluid loss for each of the generated temperature logs. This increase was quantified by computing the ratio of the slope of the temperature profile above the loss zone to the slope below the loss zone. Since the borehole temperature was considered to approach steady-state after 10 days, the temperature slope could be approximated using a linear gradient. The relationship between the gradient ratio and the percentage of fluid loss under different flow rates is illustrated in Fig. 7. The non-monotonic relationship between the gradient ratio and the fluid loss (with maximum temperature gradient ratios occurring when the fluid loss exceeds 95\%), which has already been discussed earlier, is observed for each flow rate under consideration. Moreover, the dependence of the gradient ratio on the flow rate seems to be more complex. The gradient ratio tends to be independent of the flow rate if the percentage of fluid loss is low, e.g., $<30 \%$. For fluid losses $>30 \%$, smaller temperature gradient ratios are observed for lower flow rates. However, for flow rates greater than $20 \mathrm{~L} / \mathrm{s}$ (flow velocity $>0.5 \mathrm{~m} / \mathrm{s}$ ), 


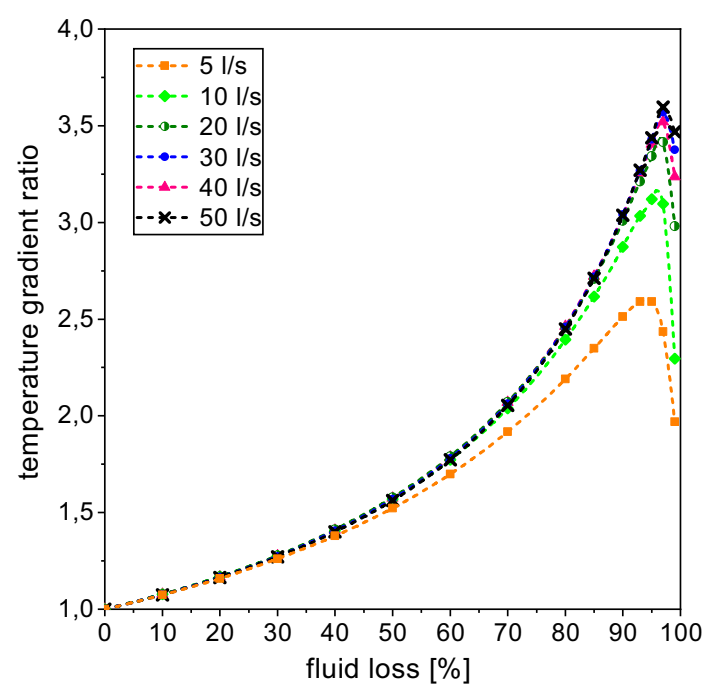

Fig. 7 The ratio of temperature gradient below the fluid loss zone (3.35 km depth) to the gradient above the fluid loss zone versus the percentage of fluid loss (S-shaped SFT profile is assumed)

the gradient ratio is almost independent to the flow rate except when the fluid loss is greater than $90 \%$.

\section{Conclusion}

The assessment of geothermal reservoirs relies on the information supplied by logging tools, with temperature logs among the most important ones. The in-house numerical tool developed to simulate the thermal response of the wellbore and the formation during fluid circulation and shut-in conditions is intended to fill the absence of a quantitative interpretation of temperature logs and the associated uncertainties. It accounts especially for the heat transfer process from the formation towards the specific location of the measurement tools including the drill pipe, annulus or open borehole. Particular care is given to the correct treatment of the transient heat transfer through the multiple interfaces (casing-annulus-drill pipe-drill fluid) in such a complex thermal system. The quality of the simulation tool was demonstrated by comparison with borehole temperatures from analytical solutions. In this study, the simulator was applied to generate synthetic shut-in and dynamic temperature logs.

The temperature logs were interpreted for two purposes: SFT estimation and characterization of loss zones. The major findings and the underlying messages conveyed in this study are as follows:

1. The shut-in temperature depends significantly on the magnitude of free convection, which enhances the heat transfer rate. In this study, a maximum difference of $30{ }^{\circ} \mathrm{C}$ in BHT predictions between the two extrema scenarios of free convection is found. In this regard, a careful parameterization of the heat transfer rate is especially important in the early transient stage of shut-in heat recovery.

2. The Horner-plot method may strongly underestimate the SFT if early shut-in (within $24 \mathrm{~h}$ ) temperature measurement data are used. However, it provides high accuracy 
SFT estimates (percentage error $<3 \%$ ) when using long-term shut-in (2 days up to 4 days) temperature measurement data.

3. Using temperature logs obtained under borehole cooling conditions can become inauspicious for the Horner-plot interpretation method even at small cooling flow rates. This can yield significant errors $\left(24{ }^{\circ} \mathrm{C}\right.$ and $74{ }^{\circ} \mathrm{C}$ at a flow rate of $0.7 \mathrm{~L} / \mathrm{s}$ for a linear- and S-shaped SFT, respectively) in the bottom-hole SFT estimation.

4. In the presence of fluid loss, the local temperature gradient change is affected by the flow rate, the percentage of fluid loss as well as the overall rate of the lateral heat transfer from the formation to the borehole fluid. It was found that for fluid losses less than $30 \%$, or under relatively high flow rates $(>20 \mathrm{~L} / \mathrm{s})$, the gradient change can be independent on the flow rates.

Under the specific conditions of high-temperature boreholes the temperature logging data represent a complex response to the wellbore layout, the flow conditions, the heat transfer mechanism, etc. Under these constraints, a simple interpretation of temperature logs can be strongly misleading and more sophisticated techniques accounting for key factors by numerical simulation are required. Herein, the impacts of these factors were investigated by individual sensitivity analysis. However, in real geothermal applications, these impacts may overlap. Therefore, simulations in this context need to be joined by inverse procedures. In this way, the present contribution represents an important step towards a more sophisticated interpretation of real project data. It requires accounting, in a detailed manner, for the geometrical setting, on the history of injection, drilling, logging (even the time lapse of logging start to logging end) and on the appraisal of measurement errors. Work is now underway to interpret dynamic temperature logs using inverse modeling techniques.

\section{List of symbols}

\section{Roman letters}

$T$ : temperature $(\Theta)$; $c_{\text {p }}$ : specific heat capacity $\left(L^{2} T^{-2} \Theta^{-1}\right)$; $t$ : time $(T)$; $r$ : radius $(L)$; $v$ : velocity $\left(L T^{-1}\right)$; $z$ : axial coordinate $(L) ;$ ij: simulation region number; $H$ : depth $(\mathrm{L})$; $m$ : mass flow rate $\left(\mathrm{M} \mathrm{T}^{-1}\right)$; $A$ : cross-section area $\left(\mathrm{L}^{2}\right) ; \mathrm{q}$ : heat flux $\left(\mathrm{M} \mathrm{T}^{-3}\right)$; $T$ s: shut-in temperature $(\Theta)$; $T_{i}$ : static formation temperature $(\Theta)$; $t_{s}$ : shut-in time $(T)$; $t_{c}$ : circulation time $(T)$; $h$ : heat transfer coefficient $\left(\mathrm{M} \mathrm{T}^{-3} \Theta^{-1}\right)$; Nu: Nusselt number (1); Pr: Prandt number (1); d: diameter (L); $L$ : length (L); $\triangle T$ : temperature difference $(\Theta) ; \nabla T$ : temperature gradient $\left(\Theta \mathrm{L}^{-1}\right) ; D_{\mathrm{T}}$ : thermal diffusivity $\left(\mathrm{L}^{2} \mathrm{~T}^{-1}\right)$; $\mathrm{C}$ : constant; $\mathrm{SFT}$ : static formation temperature; $\mathrm{BHT}$ : bottom-hole temperature; HM: Horner-plot method.

\section{Greek letters}

$\rho$ : density $\left(\mathrm{ML}^{-3}\right) ; \lambda$ : thermal conductivity $\left(M L T^{-3} \Theta^{-1}\right) ; \Gamma$ : interfacial region; $\mu$ : dynamic viscosity $\left(\mathrm{ML}^{-1} \mathrm{~T}^{-1}\right) ; \gamma$ : weighting coefficient for linear interpolation; $g$ : the acceleration of gravity $\left(L T^{-2}\right)$; $a$ : thermal expansion coefficient $\left(\Theta^{-1}\right)$; $U$ : kinematic viscosity $\left(\mathrm{L}^{2} \mathrm{~T}^{-1}\right)$.

\section{Subscripts}

f: fluid; inj: injection; r: radial direction; z: axial direction; wb: wellbore; c: conduction; free: free convection; cr: critical; abs: absolute

\section{Acknowledgements}

The study is part of the DEEPEGS "Deployment of Deep Enhanced Geothermal Systems for Sustainable Energy Business" Project within European Union's Horizon 2020 research and innovation program. The support from both the Helmholtz portfolio project "Geoenergy" and the program "Renewable Energies", under the topic "Geothermal Energy Systems", is also gratefully acknowledged. We also thank the EnBW Energie Baden-Württemberg AG for supporting geothermal research at KIT. Special thanks to Dr. Emmanuel Gaucher (KIT) for the support on the DEEPEGS project and to Dr. Steinthor Nielsson (ISOR), a partner in the DEEPEGS project. The authors would also like to thank Dr. Thorsten Agemar (Leibniz Institute for Applied Geophysics, Hannover, Germany) for fruitful discussions during the preparation of this paper. We also thank two anonymous reviewers who helped to improve the quality of this manuscript. 


\begin{abstract}
Authors' contributions
JW performed the numerical modeling, analysis of the results and wrote the manuscript. FN supervised and provided support in the design of the study. MG provided the numerical simulation tool applied in this study. TK supervised the research and finalization of the manuscript. All authors read and approved the final manuscript.

Funding

The research was funded by the European Union's HORIZON 2020 research and innovation program under Grant Agreement No. 690771.

Availability of data and materials

Data on which conclusions of the manuscript are based on are presented in the text, otherwise, they are adequately cited.

Competing interests

The authors declare that they have no competing interests.
\end{abstract}

\title{
Appendix
}

Appendix A. Validation of the Ramey's heat transmission model

Most of the literature on wellbore heat transmission is based on the classical work of Ramey (Ramey 1962, 1964). A simple physical model that describes the wellbore heat transmission consists of fluid flow in a straight, non-cased, one-dimensional well which is embedded in the two-dimensional formation. Ramey derived an analytical solution for the transient temperature distribution in injection and production wells based on simplified heat balances. However, it was found that Ramey's solution is normally valid for long times but is significantly inaccurate for early-stage transient periods. A number of studies have attempted to adjust Ramey's solution and derive more efficient and stable approximations to small, medium, and large-time solutions by giving specific expressions in terms of the so-called dimensionless time function which represents the transient heat transfer from wellbore to the formation (Kutasov 1987, 2003; Wu and Pruess 1988; Hagoort 2004; Kutun et al. 2014, 2015). In this work, we adopted the simplified expression for dimensionless time function given by Kutun et al. (2015), which is based on the best curve fit of Ramey's dimensionless time function data.

The injection and production cases were modeled by considering three different scenarios: (i) water being injected at the same temperature as the surface temperature; (ii) water being injected at a higher temperature than the surface temperature; (iii) water being extracted from the reservoir. The model set up and geometry and thermal properties data used in the simulations were the same as defined in "Shut-in temperature logs simulation", except that the well with 0.15 m radius is simplified as a one-dimensional structure.

Figure 8 presents a comparison of temperatures obtained from analytical solutions given by Ramey (Ramey 1962) and our numerical models. Maximum temperature differences (errors) for the three different simulations on day 1 , day 5 and day 10 , respectively. Case (i): $|\Delta T|_{\max } \leq 1.9^{\circ} \mathrm{C}$, case (ii): $|\Delta T|_{\max } \leq 0.21^{\circ} \mathrm{C}$, and case (iii): $|\Delta T|_{\max } \leq 1.9{ }^{\circ} \mathrm{C}$. 


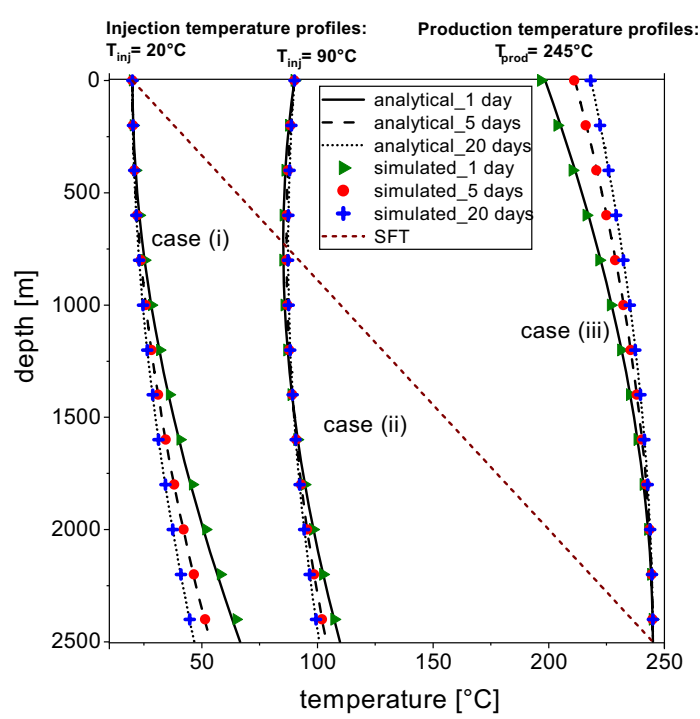

Fig. 8 Comparison of analytical and simulated solution of Ramey's heat transmission model: case (i) and case (ii) are the injection scenarios, where injection temperatures at well-head are $20^{\circ} \mathrm{C}$ and $90^{\circ} \mathrm{C}$, respectively; case (iii) is the production scenario: fluid is produced from bottom-hole at $245^{\circ} \mathrm{C}$ reservoir temperature. The analytical solution was plotted in lines: solid lines (one day), dash-dot lines ( 5 days), dot lines (20 days). The simulated solution was marked in symbols: green crosses (one day), red circle (5 days), diamonds with lower half black (20 days)

\section{Appendix B. Validation of the counterflow heat exchange model}

The counterflow heat exchange model is essentially the physical model for mud circulation under the drilling process in a wellbore. During circulation, the drilling mud flows downwards (axial direction) in the drill pipe. The heat exchange process of the system involves two mechanisms: convective heat transport and heat transfer of the drilling mud with the pipe wall (forced convection heat transfer). At the bottom, fluid exited through the drill bit into the annulus. The temperatures at the outlet of the drill pipe and the inlet of the annulus are considered to be the same. The fluid in the annulus moves upwards to the surface. The annulus fluid temperature is controlled by the rate of convective heat transport and forced convection heat transfer at two fluid-solid interfaces: annulus fluid/outer drill pipe wall, annulus fluid/wellbore wall.

The model size was $4600 \mathrm{~m}$ in the axial direction and $50 \mathrm{~m}$ in the radial direction. The mesh was discretized in $15 \mathrm{~m}$ steps in the axial direction, mesh sizes in the radial direction ranged between $10^{-3}$ and $6.5 \mathrm{~m}$. The geometric parameters of the wellbore and thermal properties data used in the modeling are given in Table 4. The analytical solution for the fluid temperature distribution inside the drill pipe and the annulus given by Bobok and Szarka (2012) was used for the numerical validation of the mud circulation model. The comparison of the analytical solution and the simulated solution of the drill pipe fluid and annulus temperature is shown in Fig. 9. Maximum estimation differences for the temperature of drill pipe fluid and annulus fluid were calculated, respectively: $0.72{ }^{\circ} \mathrm{C}, 1.06{ }^{\circ} \mathrm{C}$ after 4 days' circulation; $0.32{ }^{\circ} \mathrm{C}, 0.51{ }^{\circ} \mathrm{C}$ after 10 days' circulation; $0.08{ }^{\circ} \mathrm{C}, 0.17^{\circ} \mathrm{C}$ after 20 days' circulation (Table 4). 
Table 4 Geometric parameters and material properties used in the simulation of the counterflow heat exchange model

\begin{tabular}{lll}
\hline Property & Unit & Value \\
\hline Formation temperature at the surface & ${ }^{\circ} \mathrm{C}$ & 7 \\
The geothermal gradient & ${ }^{\circ} \mathrm{C} / \mathrm{m}$ & 0.1 \\
Casing thermal conductivity & $\mathrm{W} /\left(\mathrm{m}{ }^{\circ} \mathrm{C}\right)$ & 50 \\
Cement thermal conductivity & $\mathrm{W} /\left(\mathrm{m}{ }^{\circ} \mathrm{C}\right)$ & 1.2 \\
Formation rock density & $\mathrm{kg} / \mathrm{m}^{3}$ & 3000 \\
Formation thermal conductivity & $\mathrm{W} /\left(\mathrm{m}{ }^{\circ} \mathrm{C}\right)$ & 1.5 \\
Formation specific heat capacity & $\mathrm{J} /\left(\mathrm{kg}{ }^{\circ} \mathrm{C}\right)$ & 840 \\
Well depth & $\mathrm{m}$ & 4600 \\
Inside radius of the drill pipe & $\mathrm{m}$ & 0.0352 \\
The outside radius of the drill pipe & $\mathrm{m}$ & 0.0445 \\
Inside radius of the casing & $\mathrm{m}$ & 0.0797 \\
The outside radius of the casing & $\mathrm{m}$ & 0.089 \\
The radius of the well bore/formation interface & $\mathrm{m}$ & 0.1 \\
Water production rate & $\mathrm{kg} / \mathrm{s}$ & 15 \\
Water specific heat capacity & $\mathrm{J} /\left(\mathrm{kg}{ }^{\circ} \mathrm{C}\right)$ & 4194 \\
Water density & $\mathrm{kg} / \mathrm{m}^{3}$ & 1000 \\
Water viscosity & $\mathrm{Pa} \cdot \mathrm{s}$ & $1 \mathrm{e}-3$ \\
Water thermal conductivity & $\mathrm{W} /\left(\mathrm{m}{ }^{\circ} \mathrm{C}\right)$ & 0.6
\end{tabular}

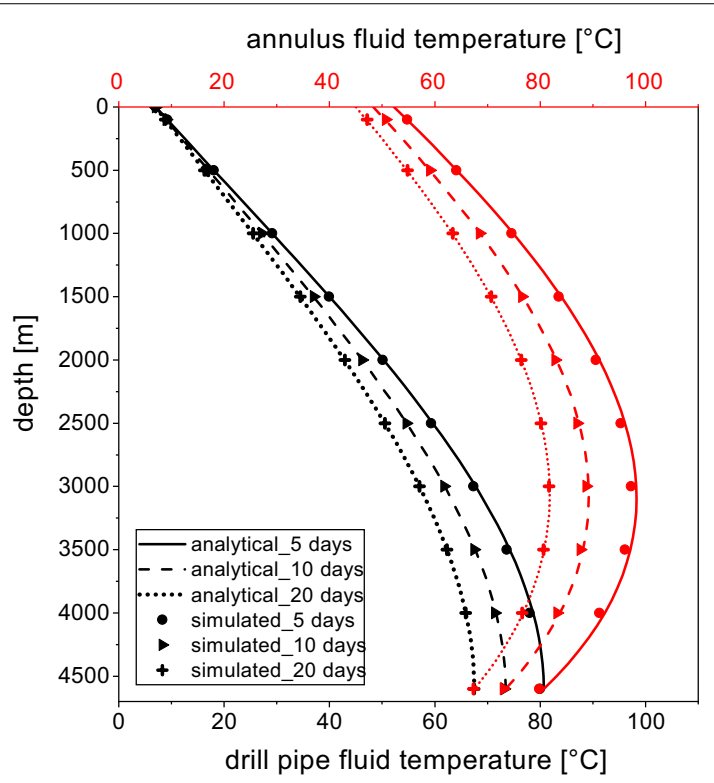

Fig. 9 Comparison of analytical solution and simulated solution for the counterflow heat exchange model. Black color represents the temperature of the fluid inside the drill pipe, red color represents the temperature of annulus fluid. Solutions were calculated and compared at three different circulation time: 5 days, 10 days, 20 days. The analytical solution was plotted in lines: solid lines ( 5 days), dash-dot lines ( 10 days), dot lines (20 days). The simulated solution was marked in symbols: circles (5 days), squares (10 days), crosses (20 days) 
Received: 23 May 2019 Accepted: 24 October 2019

Published online: 07 November 2019

\section{References}

Andaverde J, Verma SP, Santoyo E. Uncertainty estimates of static formation temperatures in boreholes and evaluation of regression models. Geophys J Int. 2005;160(3):1112-22.

Ascencio F, García A, Rivera J, Arellano V. Estimation of undisturbed formation temperatures under spherical-radial heat flow conditions. Geothermics. 1994;23(4):317-26.

Ascencio F, Samaniego F, Rivera J. Application of a spherical-radial heat transfer model to calculate geothermal gradients from measurements in deep boreholes. Geothermics. 2006;35(1):70-8.

Baird T, Fields T, Drummond R, Mathison D, Langseth B, Martin A, Silipigno L. High-pressure, high-temperature well logging, perforating and testing. Oilfield Rev. 1993;5(2/3):15-32.

Bense V, Read T, Bour O, Le Borgne T, Coleman T, Krause S, Selker J. Distributed T emperature S ensing as a downhole tool in hydrogeology. Water Resour Res. 2016;52(12):9259-73.

Berthold S, Börner F. Detection of free vertical convection and double-diffusion in groundwater monitoring wells with geophysical borehole measurements. Environ Geol. 2008;54(7):1547-66.

Bobok ZSE, Szarka Z. Determination of the temperature distribution in the circulating drilling fluid. Geosci Eng. 2012;1(1):37-47.

Bullard EC. The time necessary for a bore hole to attain temperature equilibrium. Geophys J Int. 1947:5:127-30.

Cacace M, Kaiser BO, Lewerenz B, Scheck-Wenderoth M. Geothermal energy in sedimentary basins: what we can learn from regional numerical models. Chemie der Erde-Geochem. 2010;70:33-46.

Coleman TI, Parker BL, Maldaner CH, Mondanos MJ. Groundwater flow characterization in a fractured bedrock aquifer using active DTS tests in sealed boreholes. J Hydrol. 2015;528:449-62.

Cooper J, Dooley R. Revised release on the IAPWS industrial formulation 1997 for the thermodynamic properties of water and steam. Int Assoc Properties Water Steam. 2007;1:48.

Danielsen PE. High temperature geothermal logging for temperature and pressure. Paper presented at the Conference, ARGeo C-2, Entebbe, Uganda. 2008.

Deming D. Application of bottom-hole temperature corrections in geothermal studies. Geothermics. 1989;18(5-6):775-86.

Diersch H-J, Bauer D, Heidemann W, Rühaak W, Schätzl P. Finite element modeling of borehole heat exchanger systems: part 1. Fundamentals. Comput Geosci. 2011;37(8):1122-35.

Diment WH. Thermal regime of a large diameter borehole: instability of the water column and comparison of air-and water-filled conditions. Geophysics. 1967;32(4):720-6.

Diment WH, Urban TC. Simple method for detecting anomalous fluid motions in boreholes from continuous temperature logs. Paper presented at the geothermal resources: energy on tap! Geothermal resources council 1983 annual meeting. 1983.

Dittus F, Boelter L. Heat transfer in automobile radiators of the tubular type. Int Commun Heat Mass Transfer. $1985 ; 12(1): 3-22$

Dowdle W, Cobb W. Static formation temperature from well logs-an empirical method. J Petrol Technol. 1975;27(11):1326-321330.

Eppelbaum L, Kutasov I. Estimation of the effect of thermal convection and casing on the temperature regime of boreholes: a review. J Geophys Eng. 2011;8(1):R1-10.

Espinosa-Paredes G, Garcia A, Santoyo E, Hernandez I. TEMLOPIN 2: a computer program for estimation of fully transient temperatures in geothermal wells during circulation and shut-in. Comput Geosci. 2001;27(3):327-44.

Espinosa-Paredes G, Morales-Díaz A, Olea-González U, Ambriz-Garcia J. Application of a proportional-integral control for the estimation of static formation temperatures in oil wells. Mar Pet Geol. 2009;26(2):259-68.

Friðleifsson GÓ, Elders WA, Zierenberg RA, Fowler AP, Weisenberger TB, Mesfin KG, Sigurðsson Ó, Níelsson S, Einarsson G, Óskarsson F, Guðnason EÁ. The iceland deep drilling project at Reykjanes: drilling into the root zone of a black smoker analog. J Volcanol Geotherm Res. 2018. https://doi.org/10.1016/j.jvolgeores.2018.08.013.

García A, Santoyo E, Espinosa G, Hernández I, Gutierrez H. Estimation of temperatures in geothermal wells during circulation and shut-in in the presence of lost circulation. Transp Porous Media. 1998;33(1-2):103-27.

Gaston D, Newman C, Hansen G, Lebrun-Grandie D. MOOSE: a parallel computational framework for coupled systems of nonlinear equations. Nucl Eng Des. 2009;239(10):1768-78.

Gnielinski V. On heat transfer in tubes. Int J Heat Mass Transf. 2013:63:134-40.

Goutorbe B, Lucazeau F, Bonneville A. Comparison of several BHT correction methods: a case study on an Australian data set. Geophys J Int. 2007;170(2):913-22.

Gretener PE. On the thermal instability of large diameter wells_an observational report. Geophysics. 1967;32(4):727-38.

Großwig S, Hurtig E, Kühn K. Fibre optic temperature sensing: a new tool for temperature measurements in boreholes. Geophysics. 1996;61(4):1065-7.

Hagoort J. Ramey's wellbore heat transmission revisited. SPE J. 2004;9(04):465-74.

Hasan A, Kabir C. Static reservoir temperature determination from transient data after mud circulation. SPE Drilling and Completion (Society of Petroleum Engineers); (United States). 1994; 9(1)

Ikeuchi K, Doi N, Sakagawa Y, Kamenosono H, Uchida T. High-temperature measurements in well WD-1a and the thermal structure of the Kakkonda geothermal system, Japan. Geothermics. 1998;27(5-6):591-607.

Klepikova MV, Le Borgne T, Bour O, Davy P. A methodology for using borehole temperature-depth profiles under ambient, single and cross-borehole pumping conditions to estimate fracture hydraulic properties. J Hydrol. 2011:407(1-4):145-52 
Klepikova MV, Roques C, Loew S, Selker J. Improved characterization of groundwater flow in heterogeneous aquifers using granular polyacrylamide (PAM) gel as temporary grout. Water Resour Res. 2018;54(2):1410-9.

Kohl T, Brenni R, Eugster W. System performance of a deep borehole heat exchanger. Geothermics. 2002;31(6):687-708.

Konrad F, Savvatis A, Wellmann F, Zosseder K. Hydraulic behavior of fault zones in pump tests of geothermal wells: a parametric analysis using numerical simulations for the Upper Jurassic aquifer of the North Alpine Foreland Basin. Geotherm Energy. 2019;7(1):1-28.

Kruszewski M, Wittig V. Review of failure modes in supercritical geothermal drilling projects. Geotherm Energy. 2018;6(1):28.

Kutasov I. Dimensionless temperature, cumulative heat flow and heat flow rate for a well with a constant bore-face temperature. Geothermics. 1987;16(5-6):467-72.

Kutasov I. Dimensionless temperature at the wall of an infinite long cylindrical source with a constant heat flow rate. Geothermics. 2003;32(1):63-8.

Kutasov I, Eppelbaum L. Determination of formation temperature from bottom-hole temperature logs—a generalized Horner method. J Geophys Eng. 2005;2(2):90-6.

Kutasov I, Eppelbaum L. Utilization of the Homer plot for determining the temperature of frozen formations-a novel approach. Geothermics. 2018;71:259-63.

Kutun K, Tureyen OI, Satman A. Temperature behavior of geothermal wells during production, injection and shut-in operations. In: Paper presented at the proceedings, 39th workshop on geothermal reservoir engineering, Stanford University, Stanford, California. 2014.

Kutun K, Tureyen OI, Satman A. Analysis of wellhead production temperature derivatives. In: Paper presented at the Proc 40th workshop on geothermal reservoir engineering, Stanford University. 2015.

Laarossi I, Quintela-Incera MÁ, López-Higuera JM. Comparative experimental study of a high-temperature raman-based distributed optical fiber sensor with different special fibers. Sensors. 2019;19(3):574.

Luheshi M. Estimation of formation temperature from borehole measurements. Geophys J Int. 1983;74(3):747-76.

Nian Y-L, Cheng W-L, Han B-B, Li Y-Q, Yu W-J. A novel method for predicting gas/oil flow rate from temperature log data. J Petrol Sci Eng. 2015;133:801-9.

Oullivan M, Oullivan J. Reservoir modeling and simulation for geothermal resource characterization and evaluation. Geothermal power generation. New York: Elsevier; 2016. p. 165-99.

Okandan E. Geothermal reservoir engineering, vol. 150. New York: Springer Science \& Business Media; 2012.

Pehme P, Parker B, Cherry J, Greenhouse J. Improved resolution of ambient flow through fractured rock with temperature logs. Groundwater. 2010;48(2):191-205.

Permann CJ, Andrs D, Peterson JW, Gaston DR. Massive hybrid parallelism for fully implicit multiphysics. 2013.

Pfister M, Rybach L. High-resolution digital temperature logging in areas with significant convective heat transfer. Geothermics. 1995;24(1):95-100.

Ramey H Jr. Wellbore heat transmission. J Petrol Technol. 1962;14(04):427-35.

Ramey H Jr. How to calculate heat transmission in hot fluid injection. Pet Eng. 1964;36:1 10

Read T, Bense V, Bour O, Le Borgne T, Lavenant N, Hochreutener R, Selker JS. Thermal-plume fibre optic tracking (T-POT) test for flow velocity measurement in groundwater boreholes. 2015.

Read T, Bour O, Bense V, Le Borgne T, Goderniaux P, Klepikova MV, Hochreutener R, Lavenant N, Boschero V. Characterizing groundwater flow and heat transport in fractured rock using fiber-optic distributed temperature sensing. Geophys Res Lett. 2013;40(10):2055-9.

Reinsch T, Dobson P, Asanuma H, Huenges E, Poletto F, Sanjuan B. Utilizing supercritical geothermal systems: a review of past ventures and ongoing research activities. Geotherm Energy. 2017;5(1):16.

Reinsch T, Henninges J, Ásmundsson R. Thermal, mechanical and chemical influences on the performance of optical fibres for distributed temperature sensing in a hot geothermal well. Environ Earth Sci. 2013;70(8):3465-80.

Sekine K, Bignall G, Tsuchiya N. Application of synthetic fluid inclusions to simultaneous temperature-pressure logging in high-temperature (sub-to supercritical) geothermal systems. Geothermics. 2004;33(6):775-93.

Shen P, Beck A. Stabilization of bottom hole temperature with finite circulation time and fluid flow. Geophys I Int. 1986;86(1):63-90.

Steingrimsson B. Geothermal well logging: temperature and pressure logs. Short course V on conceptual modelling of geothermal systems. 2013

Verma SP, Andaverde J, Santoyo E. Application of the error propagation theory in estimates of static formation temperatures in geothermal and petroleum boreholes. Energy Convers Manage. 2006a:47(20):3659-71.

Verma SP, Andaverde J, Santoyo E. Statistical evaluation of methods for the calculation of static formation temperatures in geothermal and oil wells using an extension of the error propagation theory. J Geochem Explor. 2006b;89(1-3):398-404.

Witterholt, E., \& Tixier, M. (1972). Temperature logging in injection wells. Paper presented at the Fall Meeting of the Society of Petroleum Engineers of AIME.

Wong-Loya J, Andaverde J, Santoyo E. A new practical method for the determination of static formation temperatures in geothermal and petroleum wells using a numerical method based on rational polynomial functions. J Geophys Eng. 2012;9(6):711-28.

Wu Y-S, Pruess K. An analytical solution for wellbore heat transmission in layered formations. 1988.

Yang M, Li X, Deng J, Meng Y, Li G. Prediction of wellbore and formation temperatures during circulation and shut-in stages under kick conditions. Energy. 2015;91:1018-29.

\section{Publisher's Note}

Springer Nature remains neutral with regard to jurisdictional claims in published maps and institutional affliations. 